九州大学学術情報リポジトリ

Kyushu University Institutional Repository

\title{
Performance Comparative of Modified Jatropha Based Nanofluids in Orthogonal Cutting Process
}

Nor Athira Jamaluddin

Faculty of Mechanical and Manufacturing Engineering, Universiti Tun Hussein Onn Malaysia

Talib, Norfazillah

Faculty of Mechanical and Manufacturing Engineering, Universiti Tun Hussein Onn Malaysia

Amiril Sahab Abdul Sani

Faculty Manufacturing Engineering, Universiti Malaysia Pahang

https://doi.org/10.5109/4480729

出版情報: Evergreen. 8 (2)，pp.461-468，2021-06. Transdisciplinary Research and Education Center for Green Technologies, Kyushu University

バージョン :

権利関係 : 


\title{
Performance Comparative of Modified Jatropha Based Nanofluids in Orthogonal Cutting Process
}

\author{
Nor Athira Jamaluddin ${ }^{1}$, Norfazillah Talib ${ }^{1, *}$, Amiril Sahab Abdul Sani ${ }^{2}$ \\ ${ }^{1}$ Faculty of Mechanical and Manufacturing Engineering, Universiti Tun Hussein Onn Malaysia, Batu Pahat, \\ Johor, Malaysia \\ ${ }^{2}$ Faculty Manufacturing Engineering, Universiti Malaysia Pahang, Pekan, Pahang, Malaysia
}

*Author to whom correspondence should be addressed:

E-mail: fazillah@uthm.edu.my

(Received January 7, 2021; Revised April 26, 2021; accepted April 26, 2021).

\begin{abstract}
As machining operation is getting crucial, thus nanotechnology has been considered in providing more effective performance to reduce friction coefficient and wear protection of both workpiece and tool. This study investigated effect of an inclusion of solid nanoparticle additives such hexagonal boron nitride (hBN), graphene, copper oxide $(\mathrm{CuO})$ at 0.05 wt.\% concentration in modified jatropha (MJO) based oil. The performance of nanofluids was evaluated by conducting friction and wear test via four-ball test as well as machining process through orthogonal cutting process. The attained results were then compared with synthetic ester. This present study revealed the MJO nanofluids (MJO + 0.05 wt.\% hBN, MJO + 0.05 wt.\% graphene and MJO + 0.05 wt.\% $\mathrm{CuO}$ ) showed higher lubrication performance as compared to the commercial synthetic ester in term of physical properties and tribological behaviour. This condition resulted in the excellent machining performance which was explained by the reduction in maximum cutting temperature, chip thickness, effect of morphology chip and tool-chip contact length. Therefore, the MJO nanofluids can be considered as a potential sustainable metalworking fluid to replace the usage of the currently used synthetic ester in machining operation.
\end{abstract}

Keywords: Modified jatropha oil, hexagonal boron nitride, graphene, copper oxide, nanofluid, orthogonal cutting

\section{Introduction}

The increasing concern on the environmental and health issues lead to industrial demand of developing biodegradable materials and more eco-green products ${ }^{1-3}$. The depletion of fossil fuel resources i.e. petroleum has attracted the attention of the research to shift to the renewable and biodegradable source ${ }^{4-7}$. Approximately $85 \%$ of metalworking fluids (MWFs) in industrial applications have been derived from petroleum-based oil which are due to their good lubrication capacity and high stability with a significant long lifetime ${ }^{8)}$. However, the use of vegetable oils as a replacement of the conventional MWF is not widely spread in the industrial applications. Vegetable oils provide desirable characteristics including high biodegradability and low toxicity towards the environment and human since it is derived from edible and non-edible plants. Nabila et al. ${ }^{9)}$ reported that the nonedible oils are more preferrable as a feedstock because of their availability at a reasonable price as compared to the edible oil. This materials selection may also significantly minimize the contamination of water sources and the burden of sewage treatment.
Moreover, the advancement of nanotechnology has gained significant attention in various industrial applications $^{10-14)}$. Recently, nanofluids have been introduced as a new production of lubricant since the existing lubricant was inefficiency to play their role as an anti-friction and wear protection agent during the operation process. Nanofluid is a combination of nanoparticles which the size typically ranges between 1 to $100 \mathrm{~nm}$ that is added into the based oil fluids either mineral oil or vegetable oil ${ }^{15)}$.

Mishra \& Baghel $^{16)}$ reported the turning process of aero engineering alloy (Ti-6Al-4V) using of graphene nanoparticles in canola oil. The findings revealed that the inclusion of graphene nanoparticles in canola oil increased the thermal conductivity of the nanofluid as compared to pure canola oil. This scenario suggested a better reduction of friction among the tool and chip contact surface was significantly provided by incorporating the nanoparticles into the oil. It was recorded that the graphene-based nanofluids exhibited good machining performance by recording the decrement to the cutting force, cutting temperature and increasing tool life and wear of the 
cutting tool. Kumar et al. ${ }^{17)}$ performed a research work on the tribological behaviour of copper $(\mathrm{Cu})$ nanoparticles in refined soybean oil (RSBO) with 1 vol.\% Zinc dialkyldithiophosphates (ZDDP) at the concentration of 0.04, 0.05, 0.1 and 0.2 wt.\% though pin-on-disc tribotester. The finding reported that $0.05 \mathrm{wt} . \%$ was considered as the optimum concentration of copper oxide (CuO) nanoparticles by showing the reduction of wear compare to pure base oil and other $\mathrm{CuO}$ nanofluids concentration. The COF reduced at all concentrations of $\mathrm{CuO}$ and 0.1 wt.\% provided lowest COF at $120 \mathrm{~N}$ and 1,500 rpm. Further explanation stated that the lubricant with addition of nanoparticles might induce a development of thin layer in which the mating of two rough surfaces could be avoided and it acts a carrier for the proportion of load, thereby separating the surfaces from mating to each other and resulted in wear reduction.

Yildirim et al. ${ }^{18)}$ studied the performance of the turning process for Nickel-based Inconel 625 using nanofluid MQL made from commercial vegetable oil with concentration of 0.5 and 1 vol\% hexagonal boron nitride (hBN) nanoparticles and the result was compared with pure MQL and dry cutting condition. The nanofluids MQL with $0.5 \mathrm{vol} \% \mathrm{hBN}$ showed the highest tool life with minimum amount of wear with reduction of $43 \%$ compared with pure MQL and dry cutting condition. Additionally, a smooth surface quality was achieved with addition of $0.05 \mathrm{vol} \% \mathrm{hBN}$ in MQL-based oil. The better lubricating performance of nanofluids MQL was corresponded to the ability of the nanoparticles to retain and hold the particle of oil, avoiding the cutting oil to immediate release from the cutting zone. According to the recent work by Singh et al. ${ }^{19)}$, Sirin $\&$ Kivak $^{20)}$ and Sirin et al. ${ }^{21)}$, they proved that the effectiveness of the nanofluids as a lubricant medium in machining process under MQL technique by providing better reduction in friction and wear, thus lowered the cutting force and less tool damage. Shuang et al. $^{22}$ mentioned that the temperature at cutting tool may be reduced due to the presence of nanoparticles in nanofluid, thus contributed to reduce friction at cutting zone and therefore, hardness and sharpness of cutting tool used can be maintained.

Therefore, this current works aimed to produce a new formulation of nanofluids from non-edible vegetable oil. The current study performed modification of the crude jatropha oil and combined with several types of nanoparticle additives which were $\mathrm{hBN}$, graphene and $\mathrm{CuO}$ at a concentration of $0.05 w t . \%$ to enhance the tribological behaviour in machining performance as sustainable metalworking fluids.

\section{Materials and Methods}

\subsection{Nanofluids preparation}

Nanofluids-based lubricant were prepared from crude jatropha oil by following the previous study from Jamaluddin et al. $^{23)}$. In the present investigation, crude jatropha oil was chemically modified to improve the thermal-oxidation stability of the crude oil. The MJO was produced through a transesterification process between jatropha methyl ester (JME) and trimethylolpropane (TMP) with a JME-to-TMP molar ratio of 3.5:1. Sodium methoxide $\left(\mathrm{CH}_{3} \mathrm{NaO}\right)$ that acted as a catalyst was used in order to minimize the saponification of esters.

A formulation of nanofluids was prepared by dispersing solid nanoparticle additives including hBN, graphene, $\mathrm{CuO}$ in the $\mathrm{MJO}$ at a constant concentration of $0.05 \mathrm{wt} . \%$ The blending process was conducted when the base oil reached $60{ }^{\circ} \mathrm{C}$ and stirred at $750 \mathrm{rpm}$ for at least 30 minutes. Table 1 tabulates the common physical properties of each solid nanoparticle additives and Table 2 provides the lubricant designation for this study.

The physical testing was conducted after the preparation of the lubricants, for example, kinematic viscosity and viscosity index (VI). The obtained data for all the MJO nanofluids were compared with the commercial synthetic ester (SE). SE is a metalworking fluid for minimum quantity lubricant (MQL) supplied by Nippon Oil Cooperation. The measurement of kinematic viscosity was done based on to ASTM D445 using a portable viscometer (Viscolite 700 ) at $40{ }^{\circ} \mathrm{C}$ and $100{ }^{\circ} \mathrm{C}$. VI was determined using both kinematic viscosity results of 40 and $100^{\circ} \mathrm{C}$ in accordance with ASTM D2270.

Table 1. Common physical properties of nanoparticles.

\begin{tabular}{|c|c|c|c|}
\hline \multirow{2}{*}{ Properties } & \multicolumn{3}{|c|}{ Types of nanoparticles } \\
\hline & $\mathrm{hBN}$ & Graphene & $\mathrm{CuO}$ \\
\hline $\begin{array}{l}\text { Average size of } \\
\text { nanoparticles (nm) }\end{array}$ & \multicolumn{3}{|c|}{$40-80$} \\
\hline $\begin{array}{l}\text { Shape of } \\
\text { nanoparticles }\end{array}$ & \multicolumn{2}{|c|}{ Nearly spherical } & Spherical \\
\hline Solubility in water & \multicolumn{3}{|c|}{ Insoluble } \\
\hline Density (g/cm3) & 2.3 & 2.27 & 6.31 \\
\hline $\begin{array}{l}\text { Thermal expansion } \\
\text { coefficient }\left({ }^{\circ} \mathrm{C}^{-1}\right)\end{array}$ & $1 \times 10^{-6}$ & $-8 \times 10^{-6}$ & $1.9 \times 10^{-6}$ \\
\hline
\end{tabular}

Table 2. Description of lubricant samples.

\begin{tabular}{|l|l|}
\hline Designation & \multicolumn{1}{|c|}{ Details } \\
\hline SE & Synthetic ester \\
\hline MJOh & MJO+0.05wt.\% hBN \\
\hline MJOg & MJO+0.05wt.\% graphene \\
\hline MJOc & MJO+0.05wt.\% CuO \\
\hline
\end{tabular}

\subsection{Tribological Testing}

The four-ball tribotester machine was used to measure friction and wear in accordance with ASTM D4172. The four-ball test was the most predominant tribological test in evaluating the friction and wear mechanism which commonly used in the lubricant oil industry. Table 3 shows the details of test condition for conducting four-ball test. Prior to the tribological performance, coefficient of 
friction (COF) was automatically calculated using Winducom 2010 and an optical camera was used to measure the wear scar diameter (WSD) of the stationary steel balls.

Table 3. Conditions for four-ball testing.

\begin{tabular}{|l|l|}
\hline Description & \multicolumn{2}{|c|}{ Details } \\
\hline Ball material & Chrome steel ball (AISI 52100) \\
\hline Diameter of ball (mm) & 12.7 \\
\hline Hardness of ball (HRC) & 64 to 66 \\
\hline Temperature $\left({ }^{\circ} \mathrm{C}\right)$ & $75 \pm 2$ \\
\hline Speed (rpm) & 1200 \\
\hline Duration (min) & 60 \\
\hline Normal load $(\mathrm{N})$ & $392 \pm 2$ \\
\hline
\end{tabular}

\subsection{Setup for orthogonal cutting}

Machining evaluation was conducted through orthogonal cutting process using a computer numeric control (CNC) turning machine (model: ROMI C420) at a constant feed rate of $350 \mathrm{rpm}$ and cutting speed (0.08 $\mathrm{mm} / \mathrm{rev}$ ) as displayed in Fig. 1. Table 4 indicates the machining parameter involved in the orthogonal cutting process. In this current study, a new surface of cutting tool and workpiece material were mounted to the jig at every beginning of each series of experiment. The cutting tool used was uncoated carbide (Kennametal SPGN120308) that was installed to the modified tool holder used (CSDPN 2525M12).

The outputs machining parameter i.e., maximum cutting temperature, tool-chip contact length, chip thickness and chip morphology were collected. The maximum cutting temperature from the thermal imager camera (FLIR T640) was observed at a range of 0 to $1000^{\circ} \mathrm{C}$. The camera was focused particularly on the axial direction during the machine operation. The setting of the camera in respect of emissivity and reflected ambient temperature were subjected to 1 and $28^{\circ} \mathrm{C}$, respectively. The chip thickness was measured using tapered nosed micrometer and the average value was calculated from ten samples of the deformed chip produced during the cutting process. Finally, the tool maker microscope was used to measure tool-chip contact length.

Table 4. Machining conditions for orthogonal cutting process.

\begin{tabular}{|l|c|}
\hline Description & Details \\
\hline Cutting speed, $V_{c}(\mathrm{~m} / \mathrm{min})$ & 350 \\
\hline Feed rate, $f_{r}(\mathrm{~mm} / \mathrm{rev})$ & 0.08 \\
\hline Width of cut, $w(\mathrm{~mm})$ & 2 \\
\hline Rake angle, $\alpha(\mathrm{o})$ & +5 \\
\hline MQL input pressure $(\mathrm{MPa})$ & 0.4 \\
\hline Nozzle angle $\left({ }^{\circ}\right)$ & 45 \\
\hline Nozzle distance $(\mathrm{mm})$ & 8 \\
\hline
\end{tabular}

\begin{tabular}{|l|c|}
\hline Nozzle inner diameter $(\mathrm{mm})$ & 2.5 \\
\hline Oil flow rate $(l / \mathrm{h})$ & 0.16 \\
\hline
\end{tabular}
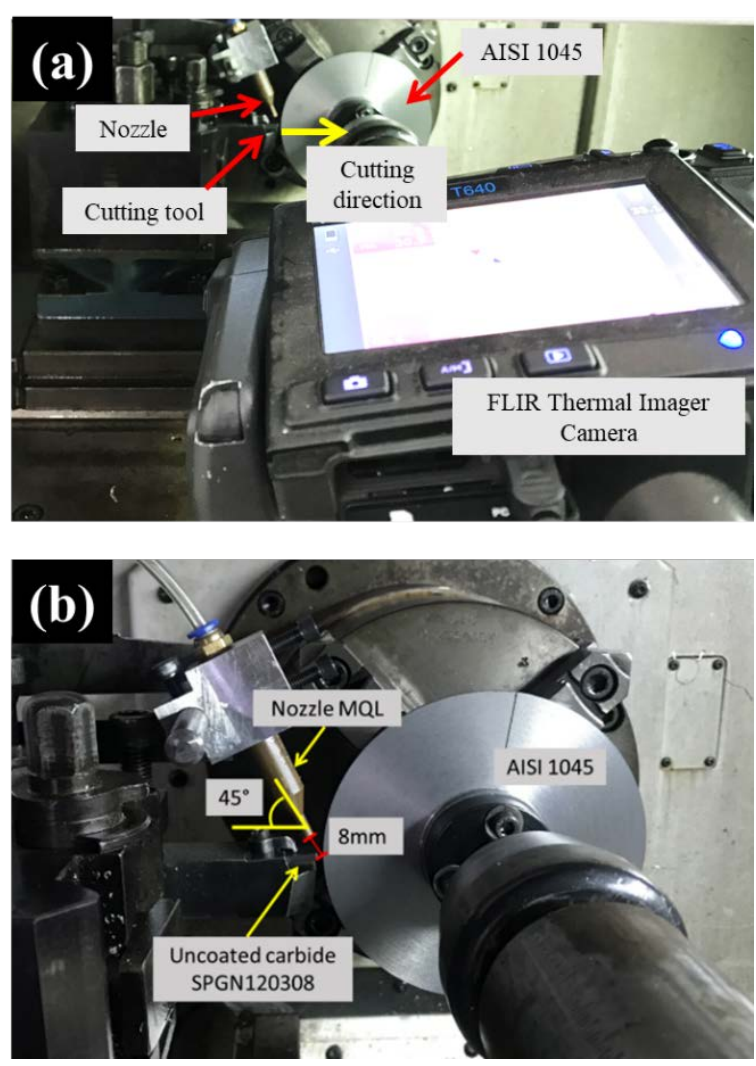

Fig. 1: (a) Setup for orthogonal cutting process, (b)location of the MQL nozzle

\section{Results and Discussion}

\subsection{Physicochemical properties of nanofluids}

Table 5 and Fig. 2 presents kinematic viscosity measured at both 40 and $100{ }^{\circ} \mathrm{C}$ and calculated value of viscosity index for SE and MJO nanofluids. As can be observed, at $40{ }^{\circ} \mathrm{C}$, the kinematic viscosity of SE for was around $19.14 \mathrm{~mm}^{2} / \mathrm{s}$ which was markedly higher than the MJO nanofluid. This scenario showed the SE that was formulated with the inclusion of various packages of additives such as viscosity improver, anti-wear additives and corrosion inhibitor, thus resulted in increasing viscosity of $\mathrm{SE}^{24)}$. Meanwhile, MJO samples showed lower kinematic viscosity which was attributed to the change of MJO composition after undergoing a chemical modification. The intermolecular forces on the hydrogen bond was weakened, thus reduced the viscosity of the oil ${ }^{25)}$. Interestingly, the the kinematic viscosity was improved with the addition of nanoparticles in MJO. Apparently, the highest kinematic viscosity at $40^{\circ} \mathrm{C}$ was recorded by $\mathrm{MJOg}$, followed by $\mathrm{MJOh}$ and MJOc. Meanwhile, MJOg possessed the highest kinematic viscosity at $100{ }^{\circ} \mathrm{C}$ (i.e., $5.23 \mathrm{~mm}^{2} / \mathrm{s}$ ) among the other samples. This phenomenon was explained by its high viscosity index of 272. Increasing viscosity of the 
lubricant resulted in increasing VI value, as the VI was significantly affected by the lower coefficient of thermal expansion of graphene $\left(-8 \times 10^{-6} /{ }^{\circ} \mathrm{C}\right)^{26)}$ compared to hBN $\left(1 \times 10^{-6} /{ }^{\circ} \mathrm{C}\right)^{27)}$ and $\mathrm{CuO}\left(1.9 \times 10^{-6} /{ }^{\circ} \mathrm{C}\right)^{28)}$.

Table 5. Physicochemical properties for all studied samples.

\begin{tabular}{|c|c|c|c|}
\hline $\begin{array}{c}\text { Sample } \\
\text { lubricant }\end{array}$ & $\begin{array}{c}\text { Kinematic } \\
\text { viscosity at } \\
40^{\circ} \mathrm{C}\end{array}$ & $\begin{array}{c}\text { Kinematic } \\
\text { viscosity at } \\
100^{\circ} \mathrm{C}\end{array}$ & $\begin{array}{c}\text { Viscosity } \\
\text { index } \\
\text { (VI) }\end{array}$ \\
\hline SE & 19.14 & 4.33 & 138 \\
\hline MJOh & 18.00 & 5.11 & 242 \\
\hline MJOg & 18.38 & 5.49 & 272 \\
\hline MJOc & 17.67 & 5.00 & 237 \\
\hline
\end{tabular}

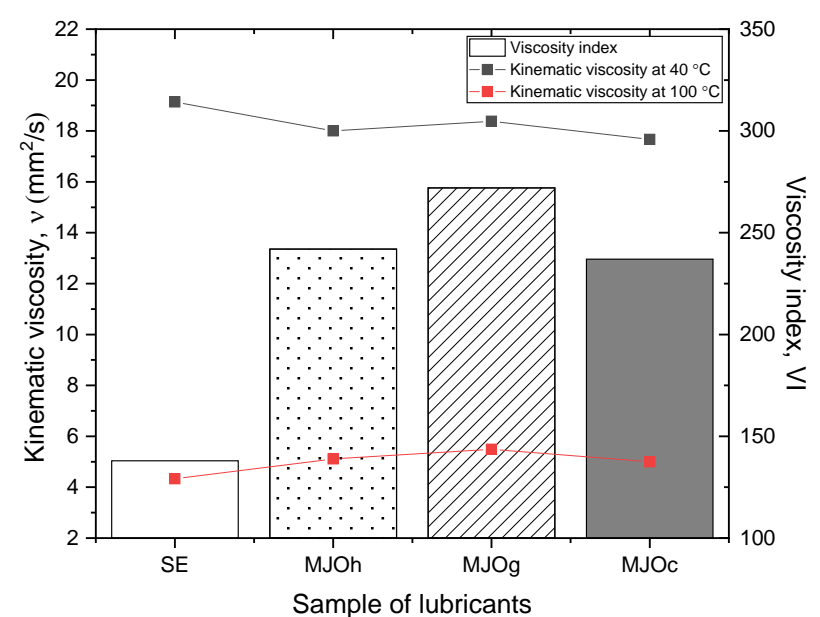

Fig. 2: Result of kinematic viscosity and VI for all studied samples.

\subsection{Coefficient of friction and wear scar diameter}

Fig. 3 indicates the tribological behavior of COF and WSD of the studied lubricant samples. The excellent tribological performance recorded by the MJO nanofluids in contrast with SE. This finding was due to the formation of molecular chains and branched in the MJO that provided a stronger protective film than $\mathrm{SE}^{27)}$. Fig. 3 shows the improved the lubricant performance of MJO nanofluids provided a significant reduction of both COF and WSD in between $37.4-50.6 \%$ and $35.4-47.7 \%$ respectively. This observation explained that the addition of the nanoparticles in MJOs filled the inter-asperity valley of the sliding metallic surfaces which were not smooth, thus providing rolling mechanism and could result in a formation of thin transfer films that led to an effective lubrication ${ }^{29)}$. Clearly, MJOc showed the lowest COF (0.0442) followed by MJOg (0.0531) and MJOh (0.056). The spherical profile of the $\mathrm{CuO}$ nanoparticles was uniformly retained after the diffusion which was attributed to the higher density of bulk nano $\mathrm{CuO}$ than the graphene and hBN nano particles, hence contributed in lowering the frictional coefficient ${ }^{30)}$. However, MJOc offered the highest WSD compared to MJOg and MJOh. In addition, MJO incorporated with hBN and graphene produced low COF during the contact between the ball surfaces. This scenario was due to their two-dimensional (2D) layered materials that might provide lower interlayer friction and lower ability to accommodate relative surface velocity ${ }^{31)}$.

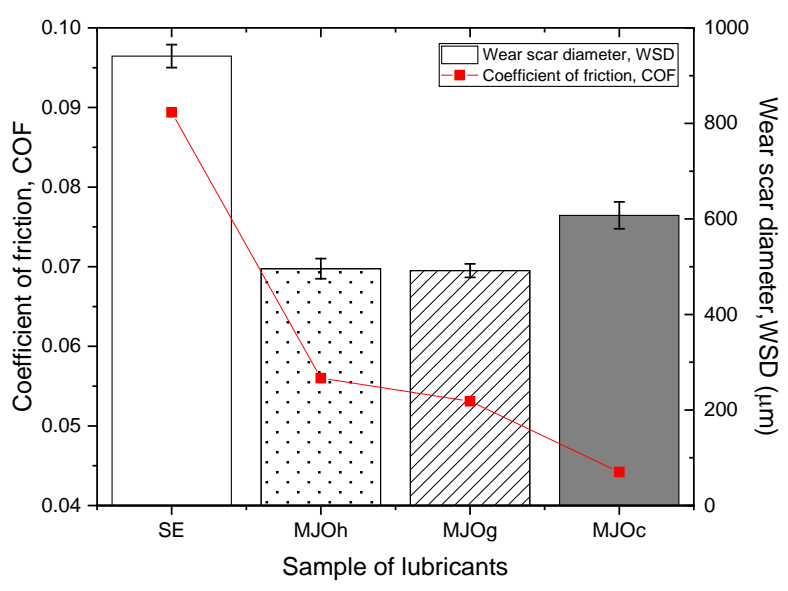

Fig. 3: COF and WSD for all lubricant samples.

\subsection{Maximum Cutting temperature}

Fig. 4 shows that SE offered lowest lubricant performance with the maximum cutting temperature of $244.1{ }^{\circ} \mathrm{C}$ in comparison to the MJO nanofluids. This finding was explained by its low VI of 138 thus resulted in incapability of the SE to sustain its characteristics at high operating temperatures. Remarkably, the MJOs sample provided the highest VI within the range of 237 to $272^{\circ} \mathrm{C}$. The better performance of lubricating oil required the higher VI to remain stable with a slight change in viscosity within the temperature range. It can be further explained that the higher VI provided a more stable molecule in the oil, thus resulted in higher lubrication over the operating range of temperature and provided a longer lubricant life ${ }^{32)}$.

According to this current study, the inclusion of nanoparticle additives in the MJO offered a reduction of the maximum cutting temperature in a range of 9.9 to $13.4 \%$ as compared to the SE. This phenomenon might be attributable to the nanoparticles additive in MJO significantly prevented the rough faces from a direct sliding contact by filling the asperities valley as well as provided rolling friction. Consequently, lower maximum cutting temperature was generated by MJOg $\left(211.5^{\circ} \mathrm{C}\right)$ and MJOh $\left(213.0{ }^{\circ} \mathrm{C}\right)$, whereas the maximum cutting temperature of MJOc was $220^{\circ} \mathrm{C}$. The hBN and graphene nanoparticles were well-known 2D layered materials which possessed low ability of interlayer friction and low ability to accommodate relative sliding surface velocity, thus resulted in the reduction of friction and heat generation $^{31)}$. 


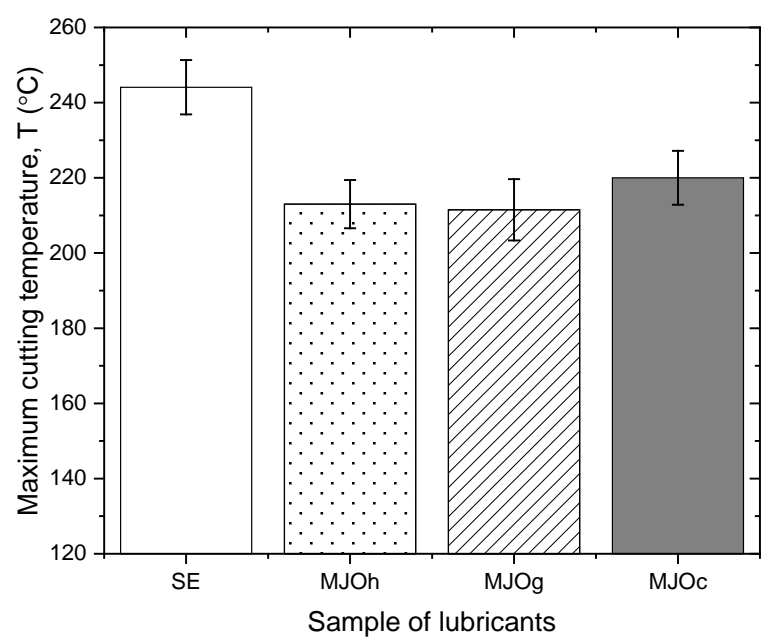

Fig. 4: Cutting temperature for all lubricant samples.

\subsection{Chip thickness}

Fig. 5 shows SE had the highest chip thickness of $0.223 \mathrm{~mm}$ as compared to the MJO nanofluids which demonstrated that the contact area at the shear zone was reduced during the machining process. This situation was due to the lubrication film that was developed by MJO in which significantly reduced the friction.

The presence of nanoparticle additives such as hBN, graphene and $\mathrm{CuO}$ in $\mathrm{MJO}$ showed the reduction in chip thickness by 19.7 to $21.0 \%$ which was significantly lower than SE. This finding was attributed to the nanoparticles in MJO significantly reduced the deformation of chip thickness. The reduction of chip thickness led to the thinner shear plane and greater shear angle, thereby, lowered the cutting force and the COF between the toolchip contact surfaces. MJOh offered the lowest chip thickness of $0.184 \mathrm{~mm}$, followed by MJOg $(0.187 \mu \mathrm{m})$ and MJOc $(0.187 \mu \mathrm{m})$. The reduction of chip thickness of MJOh was due to the alignment of the hBN particles on the metal surfaces in which parallel to the direction of motion. On the other hand, graphene with its 2D structure was easily transferred between the sliding surfaces including shears. This phenomenon explained the layer formed during the sliding was covalently bound to the layer in graphene, resulted in the reduction of friction, hence less heat was generated by the friction force ${ }^{16)}$. Moreover, the $\mathrm{CuO}$ nanoparticles might provide the lessened chip thickness due to the spherical shape of $\mathrm{CuO}$ nanoparticles that might offer a cushion effect. This effect explained how the nanoparticles absorbed the abrupt impact that diminished the cutting force fluctuations ${ }^{33}$.

Fig. 6 shows the effect of the formation of chip curling for all studied samples. As can be observed, MJOs nanofluids showed the smallest chip curvature radius compared to SE. This finding explained the smaller chip curling radius could reduce the frictional heat due to the formation of tribo-layer and higher penetration of nanofluid at the chip-tool interface ${ }^{34)}$.

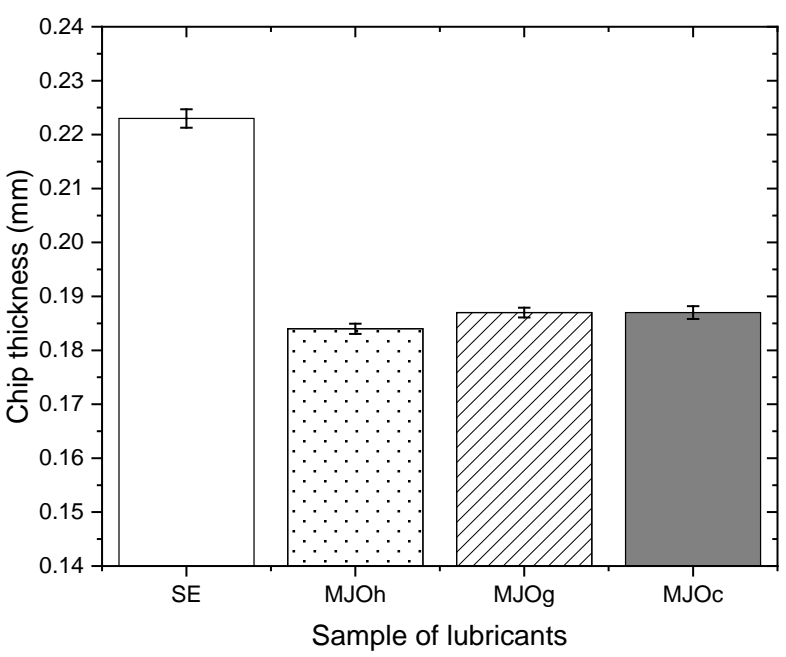

Fig. 5: Chip thickness for all lubricant
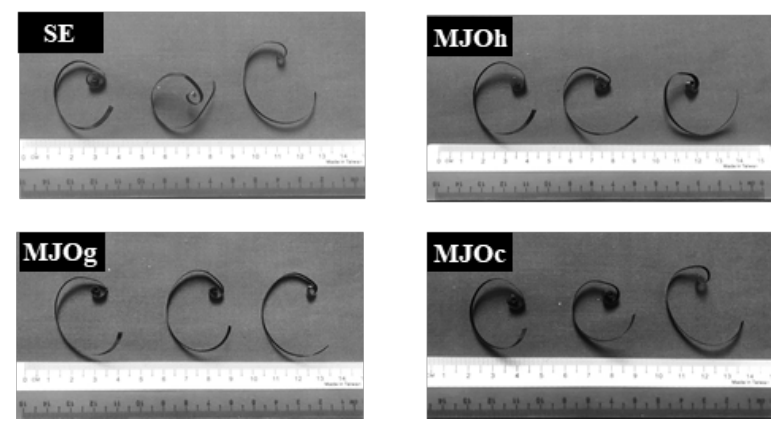

Fig. 6: Chip curling effects

\subsection{Tool chip contact length}

According to Fig. 7 and Fig. 8, SE observed the longest tool-chip length $(376.8 \mu \mathrm{m})$ as compared to the other studied MJOs. This situation was described by the shorter length of the carbon chain hence, resulted in a weaker adsorption durability between the interfaces of the tool and chip ${ }^{35)}$. This condition was confirmed that the lubricant film of SE was completely broken and could not sustain the force acting between the tool and chip. It was observed that MJO incorporated with nanoparticle additives exhibited higher lubrication property as the toolchip contact length was slightly reduced by 12.3 to $16.3 \%$ in contrast with SE. MJOh displayed the shortest tool-chip contact length of $315.3 \mu \mathrm{m}$ followed by MJOg $(317.2 \mu \mathrm{m})$ and MJOc (330.2 $\mu \mathrm{m})$. This condition was contributed to the less frictional heat generation during the deformation on the secondary shear zone, thus resulting in the shorter tool-chip contact length. An enhanced lubrication was achieved by incorporating nanoparticles in MJO based oil as the sliding region on the rake face was considerably reduced. Furthermore, the nanoparticles in MJO improved the tribological and thermo-physical properties attributable to their mechanism including the formation of tribo film and ball-bearing effect that decreased the friction generation. Thus, it can be concluded that the effectiveness of the nanoparticles was shown a significant 
enhancement on the friction between the chip and tool contact, thus providing an enhanced lubrication that might decrease cutting force and heat generation ${ }^{36)}$.

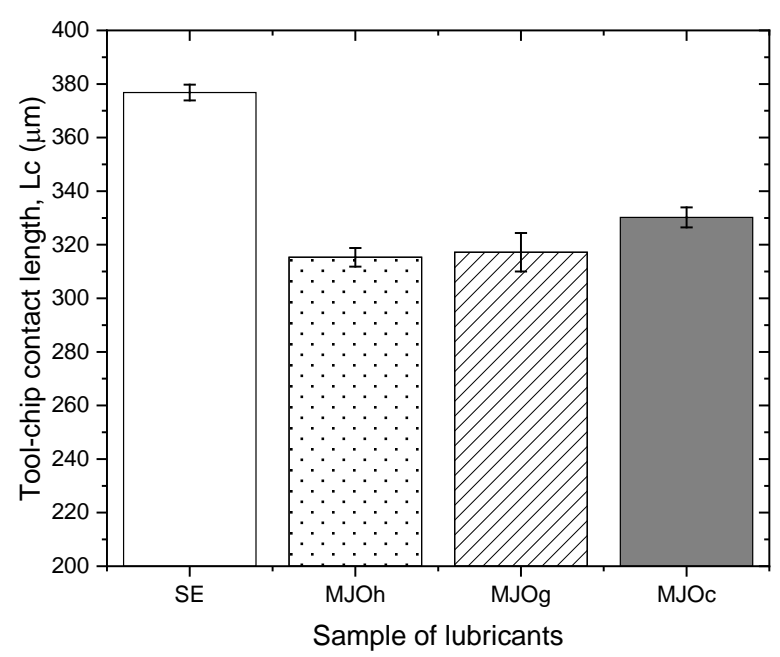

Fig. 7: Tool-chip contact length for all lubricant sample.
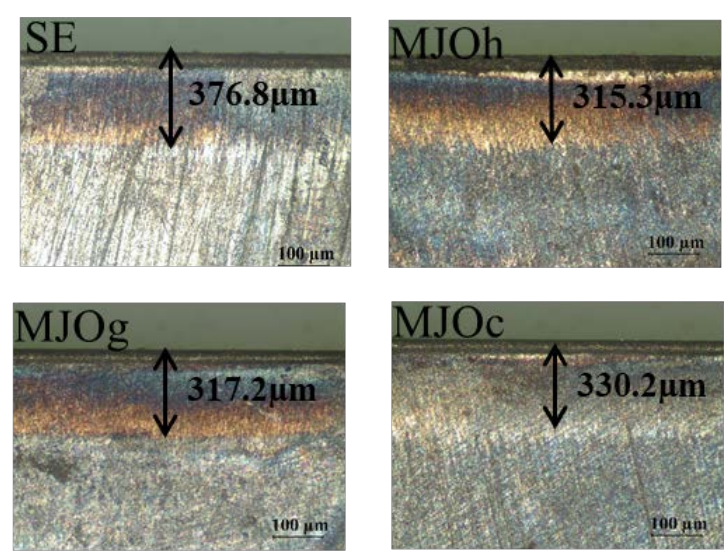

Fig. 8: Optical images of tool-chip contact length

\section{Summary}

The formulation of nanofluid by selecting of a bio-base such jatropha oil and addition of solid nanoparticles additives which considered as a carrier fluid for a sustainable metalworking fluid. A possible explanation for this lubricant development could be attributed to promote lower friction and wear together with improved machining process. From this current work, the important conclusions drawn were summarized as follows:

a) MJO nanofluids (MJO+0.05wt.\% hBN, MJO $+0.05 w \mathrm{w} . \%$ graphene and $\mathrm{MJO}+0.05 w \mathrm{w} . \% \mathrm{CuO}$ ) offered the most significant improvement of physical properties by increasing the kinematic viscosity and viscosity index. MJOg exhibited highest VI (272) followed by MJOh (242) and MJOc (237). The VI index was highly required in ensuring the sustainability of the lubricant properties during high temperature operation.

b) MJO of MJOg, MJOh and MJOc showed the lower COF and WSD as compared to the commercially used SE. This situation suggested that MJO nanofluids might provide improved performance particularly on the tribological behaviour.

c) MJO nanofluids enchanced machining performance as compared to SE that showed a reduction of maximum cutting temperature, tool-chip contact length and chip thickness.

d) Attributable to the significantly enhanced performance provided MJO nanofluids (MJOg, MJOh and MJOc) in both tribological and machining, thus it can be suggested that MJO asa new potential candidate in substituting the currently used SE as a sustainable MWF in machining application.

\section{Acknowledgements Nomenclature}

This works has initially been accepted and presented at the Mechanical Engineering Research Day 2020 (MERD'20). The authors gratefully acknowledge and sincere appreciation to the Univesiti Tun Hussein Onn Malaysia (UTHM) and Ministry of Higher Education Malaysia (MOHE) made this study possible TIER 1 Research Grant (H176) and Fundamental Research Grant Scheme Vot No. FRGS/1/2018/TK03/UTHM/03/10.

\section{Nomenclature}

$\begin{array}{ll}\text { COF } & \text { Coefficient of friction } \\ \text { Cu } & \text { Copper } \\ \text { CuO } & \text { Copper oxide } \\ \text { hBN } & \text { Hexagonal boron nitride } \\ \text { JME } & \text { Jatropha methyl ester } \\ \text { MWF } & \text { Metalworking fluids } \\ \text { MQL } & \text { Minimum quantity lubrication } \\ \text { MJOc } & \text { MJO+0.05wt.\% CuO } \\ \text { MJOg } & \text { MJO+0.05wt.\% graphene } \\ \text { MJOh } & \text { MJO+0.05wt.\% hBN } \\ \text { MJO } & \text { Modified jatropha oil } \\ \text { RSBO } & \text { Refined soybean oil } \\ \text { SE } & \text { Synthetic ester } \\ \text { TMP } & \text { Trimethylolpropane } \\ \text { VI } & \text { Viscosity index } \\ \text { WSD } & \text { Wear scar diameter } \\ \text { ZDDP } & \text { Zinc dialkyldithiophosphate }\end{array}$

\section{References}

1) D.F. Smaradhana, D. Ariawan, and R. Alnursyah, “A progress on nanocellulose as binders for loose natural fibres," Evergreen, 7 (3) 436-443 (2020). doi:10.5109/4068624.

2) Z.F. Zahara, "Economic assessment of the sugarcanebased bio-refinery in indonesia,” Evergreen, 5 (2) 6777 (2018). doi:10.5109/1936219.

3) N.K. Maurya, V. Rastogi, and P. Singh, 
"Experimental and computational investigation on mechanical properties of reinforced additive manufactured component,” Evergreen, 6 (3) 207-214 (2019). doi:10.5109/2349296.

4) M. Ayadi, S. Ahou, S. Awad, M. Abderrabba, and Y. Andres, "Production of biogas from olive pomace," Evergreen, $7 \quad$ (2) 228-233 (2020). doi:10.5109/4055224.

5) K. Marzia, M.F. Hasan, T. Miyazaki, B.B. Saha, and S. Koyama, "Key factors of solar energy progress in bangladesh until 2017,” Evergreen, 5 (2) 78-85 (2018). doi:10.5109/1936220.

6) E. Kusrini, D. Supramono, M.I. Alhamid, S. Pranata, L.D. Wilson, and A. Usman, "Effect of polypropylene plastic waste as co-feeding for production of pyrolysis oil from palm empty fruit bunches," Evergreen, 6 (1) 92-97 (2019). doi:10.5109/2328410.

7) D. Supramono, and J. Edgar, "Characteristics of nonpolar bio-oil produced by co-pyrolysis of corn cobs and polypropylene using co2 as carrier gas," Evergreen, 6 (1) 78-84 (2019). doi:10.5109/2328407.

8) M.C. de Souza, J. Fracaro de Souza Gonçalves, P. Cézar Gonçalves, S. Yuji Sudo Lutif, and J. de Oliveira Gomes, "Use of jatropha and moringa oils for lubricants: metalworking fluids more environmental-friendly,” Ind. Crops Prod., 129 594603 (2019). doi:10.1016/j.indcrop.2018.12.033.

9) S. Nabilla, S.F. Anisa, K. Zara, and S. Bismo, "Fatty acid methyl ester synthesis in the cold plasma reactor using co2 and steam mixture,” Evergreen, 7 (2) 275279 (2020). doi:10.5109/4055232.

10) W.N. Septiadi, K. Astawa, I.G.A.P. Arvikadewi, D. Febraldo, and G.J.P. Putra, "Boiling phenomenon of graphene nano-coating wick heat pipe,” Evergreen, 7 (2) 297-302 (2020). doi:10.5109/4055236.

11) I.F. Andhika, T.E. Saraswati, and S. Hastuti, "The structural characteristics of carbon nanoparticles produced by arc discharge in toluene without added catalyst or gases,” Evergreen, 7 (3) 417-428 (2020). doi:10.5109/4068622.

12) I.H. Dwirekso, M. Ibadurrohman, and Slamet, "Synthesis of tio2-sio2-cuo nanocomposite material and its activities for self-cleaning," Evergreen, 7 (2) 285-291 (2020).

13) S. Hirata, and M. Ohtaki, "Simultaneous enhancement in the electrical conductivity and reduction in the lattice thermal conductivity leading to enhanced thermoelectric zt realized by incorporation of metallic nanoparticles into oxide matrix," Evergreen, 7 (1) 1-6 (2020). doi:10.5109/2740934.

14) P.P.D.K. Wulan, J.A. Ningtyas, and M. Hasanah, "The effect of nickel coating on stainless steel 316 on growth of carbon nanotube from polypropylene waste," Evergreen, 6 (1) 98-102 (2019). doi:10.5109/2328411.

15) P. Krajnik, F. Pusavec, and A. Rashid, "Nanofluids: properties, applications and sustainability aspects in materials processing technologies," Adv. Sustain. Manuf., 107-113 (2011). doi:10.1007/978-3-64220183-7.

16) R. Mishra, and P.K. Baghel, “Application of graphene nanofluid as lubricant / coolant in turning process," Int. J. Res. Anal. Rev., 7 (2) 683-689 (2020).

17) G. Kumar, H.C. Garg, and A. Gijawara, "Experimental investigation of tribological effect on vegetable oil with cuo nanoparticles and zddp additives,” (2019). doi:10.1108/ILT-05-2018-0196.

18) Ç.V. Yildirim, M. Sarıkaya, T. Kıvak, and Ş. Şirin, "The effect of addition of hbn nanoparticles to nanofluid-mql on tool wear patterns, tool life, roughness and temperature in turning of ni-based inconel 625,” Tribol. Int., 134 (February) 443-456 (2019). doi:10.1016/j.triboint.2019.02.027.

19) S. Sirin, and T. Kivak, "Performances of different eco-friendly nanofluid lubricants in the milling of inconel x-750 superalloy,” Tribol. Int., 137 (April) 180-192 (2019). doi:10.1016/j.triboint.2019.04.042.

20) T. Kivak, "Tribology international machinability performance of nickel alloy $\mathrm{x}-750$ with sialon ceramic cutting tool under dry , mql and hbn mixed nanofluid-mql,” 153 (September 2020) (2021). doi:10.1016/j.triboint.2020.106673.

21) R.K. Singh, A.K. Sharma, A.R. Dixit, A.K. Tiwari, A. Pramanik, and A. Mandal, "Performance evaluation of alumina-graphene hybrid nano-cutting fluid in hard turning,” J. Clean. Prod., 162 830-845 (2017). doi:10.1016/j.jclepro.2017.06.104.

22) Y. Shuang, M. John, and D. Songlin, "Experimental investigation on the performance and mechanism of graphene oxide nanofluids in turning ti-6al-4v," $\mathrm{J}$. Manuf. Process., 43 (October 2018) 164-174 (2019). doi:10.1016/j.jmapro.2019.05.005.

23) N.A. Jamaluddin, N. Talib, and A.S. Abdul Sani, "Tribological analyses of modified jatropha oil with hbn and graphene nanoparticles as an alternative lubricant for machining process," J. Adv. Res. Fluid Mech. Therm. Sci., $76 \quad$ (2) 1-10 (2020). doi:10.37934/arfmts.76.2.110.

24) N.W.M. Zulkifli, H.H. Masjuki, M.A. Kalam, R. Yunus, and S.S.N. Azman, "Lubricity of bio-based lubricant derived from chemically modified jatropha methyl ester,” J. Tribol., 93 555-562 (2014). doi:10.1016/j.triboint.2015.03.024

25) C.Y. Onuh, A. Dosunmu, P.A.L. Anawe, V. Efeovbokhan, and A. Adebisi, “Transesterification of non-edible vegetable oil for lubricant applications in water-based mud: a review," Int. J. Appl. Eng. Res., 12 (18) 7397-7401 (2017).

26) D. Yoon, Y. Son, and H. Cheong, "Negative thermal expansion coefficient of graphene measured by raman spectroscopy,” Nano Lett., 11 (8) 3227-3231 (2011). doi:10.1021/nl201488g

27) N. Talib, R. Md. Nasir, E. Abd. Rahim, R.M. Nasir, 
and E.A. Rahim, "Investigation on the tribological behaviour of modified jatropha oil with hexagonal boron nitride particles as a metalworking fluid for machining process,” Int. J. Integr. Eng., 10 (3) 57-62 (2018). doi:10.30880/ijie.2018.10.03.010.

28) K. Limkrailassiri, "Copper Oxide by Thermal Oxidation for Electrochemical Cells and Gas Sensors,” Ph.D. dissertation, University of California, Berkeley (2013).

29) C.J. Reeves, P.L. Menezes, M.R. Lovell, and T.C. Jen, "The size effect of boron nitride particles on the tribological performance of biolubricants for energy conservation and sustainability,” Tribol. Lett., 51 (3) 437-452 (2013). doi:10.1007/s11249-013-0182-2.

30) S. Baskar, G. Sriram, and S. Arumugam, "Experimental analysis on tribological behavior of nano based bio-lubricants using four ball tribometer," Tribol. Ind., 37 (4) 449-454 (2015).

31) C. Chan, S.W. Tang, N.K. Mohd, W.H. Lim, and S.K. Yeong, "Tribological behavior of biolubricant base stocks and additives,” Renew. Sustain. Energy Rev., 93 145-157 (2018). doi:10.1016/j.rser.2018.05.024.

32) L.R. Rudnick, "Synthetics, mineral oils, and biobased lubricants: Chemistry and technology,” 2013. doi:10.1201/9781420027181.

33) A. Das, O. Pradhan, S.K. Patel, S.R. Das, and B.B. Biswal, "Performance appraisal of various nanofluids during hard machining of aisi 4340 steel,” J. Manuf. Process., $46 \quad 248-270 \quad$ (2019). doi:10.1016/j.jmapro.2019.07.023.

34) B.C. Behera, Chetan, D. Setti, S. Ghosh, and P.V. Rao, "Spreadability studies of metal working fluids on tool surface and its impact on minimum amount cooling and lubrication turning," J. Mater. Process. Technol., 244 1-16 (2017). doi:10.1016/j.jmatprotec.2017.01.016.

35) V. Alimirzaloo, S.S. gurchin Qaleh, P.M. Keshtiban, and S. Ahmadi, "Investigation of the effect of cuo and $\mathrm{Al}_{2} \mathrm{O}_{3}$ nanolubricants on the surface roughness in the forging process of aluminum alloy,” J. Eng. Tribol., 1-10 (2017). doi:10.1177/1350650117702816. 